\title{
WestVirginiaUniversity
}

THE RESEARCH REPOSITORY @ WVU

Graduate Theses, Dissertations, and Problem Reports

2019

\section{Stockmanship Education and Evaluation}

John K. Yost

West Virginia University, john.yost@mail.wvu.edu

Follow this and additional works at: https://researchrepository.wvu.edu/etd

Part of the Educational Methods Commons

\section{Recommended Citation}

Yost, John K., "Stockmanship Education and Evaluation" (2019). Graduate Theses, Dissertations, and Problem Reports. 4076.

https://researchrepository.wvu.edu/etd/4076

This Dissertation is protected by copyright and/or related rights. It has been brought to you by the The Research Repository @ WVU with permission from the rights-holder(s). You are free to use this Dissertation in any way that is permitted by the copyright and related rights legislation that applies to your use. For other uses you must obtain permission from the rights-holder(s) directly, unless additional rights are indicated by a Creative Commons license in the record and/ or on the work itself. This Dissertation has been accepted for inclusion in WVU Graduate Theses, Dissertations, and Problem Reports collection by an authorized administrator of The Research Repository @ WVU.

For more information, please contact researchrepository@mail.wvu.edu. 


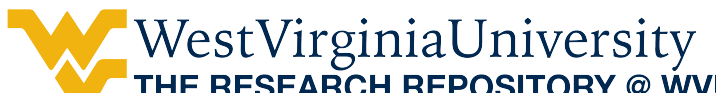

THE RESEARCH REPOSITORY @ WVU

Graduate Theses, Dissertations, and Problem Reports

2019

Stockmanship Education and Evaluation

John K. Yost

Follow this and additional works at: https://researchrepository.wvu.edu/etd

Part of the Educational Methods Commons 
Stockmanship Education and Evaluation

John K. Yost

Dissertation submitted to the Davis College of Agriculture, Natural Resources and Design at West Virginia University in partial fulfillment of the requirements for the degree of

Doctor of Philosophy

in Agriculture and Extension Education

Harry N. Boone, Jr., Ph.D., Chair Deborah A. Boone, Ph.D.

Alison M. Wilson, MD

Matthew E. Wilson, Ph.D.

School of Design and Community Development

Morgantown, West Virginia 2019

Keywords: Agricultural Education, Stockmanship, Livestock Copyright 2019 John K. Yost 


\title{
ABSTRACT \\ Stockmanship Education and Evaluation
}

\author{
John K. Yost
}

This dissertation documents two separate works. The first is an evaluation of WVU SFMS/SOIDC Large Animal Module and the second is the development and use of the Stockman's Scorecard. The WVU SFMS/SOIDC Large Animal Module provides foundational information on food animal husbandry and veterinary procedures to SOF Combat Medic candidates. A quasi-experimental design was used to determine if the module content resulted in an increase in food animal production knowledge for the participants. Seventy-five percent of the subjects had no previous livestock exposure and only seven percent had previously participated in 4-H or FFA. Matched pair analysis determined that the average improvement of scores, pre-test versus post-test, was significantly greater for those that attended the module (18.5 vs. 0.9$)$. Knowledge of food animal production can assist SOF medics in establishing rapport with indigenous population while on mission.

An animal's action, or inaction, is the direct result of a stockman's action or inaction. The Stockman's Scorecard is a novel observation instrument that has been developed to measure the quality of beef cattle stockmanship. Specific handler actions have been weighted based on their perceived negative relationship to cattle stress from handling. The purpose of Chapters II and III of this paper is to 1) establish the validity and reliability of the Stockman's Scorecard as a tool for the quantitative measurement of beef cattle stockmanship, 2) document the initial use of the scorecard in a beef cattle feedlot setting, and 3) provide further support to its validity by establishing an association with other quantitative and qualitative means of evaluating stockmanship. Face validity for the scorecard was established by a panel of experts. Reliability was determined by pilot testing at three Mid-West feedlot facilities. Trained observers evaluated 19 stockmen using the card and their scores were analyzed using a split-half methodology to calculate a Spearman-Brown coefficient. The instrument constructs were found to be exemplary (Robinson, Shaver, \& Wrightsman, 1991) with a coefficient of 0.76 exceeding the threshold of 0.30 for inter-item correlations. To determine the intra-rater reliability, three observers were shown six videos of individuals moving a group of steers from their home pen to the working chute. The observers scored each handler using the scorecard and final scores were used to calculate an intraclass correlation coefficient (ICC) using SPSS (v 25). The observers exhibited a high level of agreement with and ICC $=0.66$ which can be classified as good intra-rater reliability. The Scorecard was used at 45 beef feedlots in Texas between March 2018 and April 2019. Eighty-four stockman were observed, and the average score received was an $84.5($ Std Dev $=14.73$, range $=20-100)$. The most frequent mistakes observed were: fills crowd pen/tub over half full $(\mathrm{n}=39)$, slow to remove pressure $(n=29)$, uses unnecessary noise $(n=25)$, stands in front and taps rear $(n=24)$, and fails to regulate animal flow through a pinch point $(n=22)$. 
A strong negative association $(\rho=-0.51)$ was found between the points deducted from the Noise and Physical Contact theme of the Scorecard and the number of animals touched with an electric prod from the BQA Feedyard Assessment. Moderate negative associations were found between the Scorecard final score and the number of animals that vocalize in the chute prior to procedures $(\rho=-0.31)$. Those stockmen that scored above average on the Scorecard were qualitatively observed to be calm and quiet while working with the cattle $(\mathrm{Kappa}=0.44)$. The qualitative disposition of cattle had little effect on the final score of stockmen using the Scorecard (Kappa = 0.17). The use of the Scorecard in a feedlot setting has demonstrated that as stockman scores decrease, there is an increase in the number of negative actions towards cattle and a negative behavioral response of the cattle themselves. Establishment of an association between a stockman's score using the Stockman's Scorecard and the animal-based observations from the BQA Feedyard Assessment further strengthens the validity of the Stockman's Scorecard as a tool to measure the quality of beef cattle stockmanship. The Scorecard has application as a tool to identify specific stockmanship deficiencies in order to target stockmanship training. 


\section{DEDICATION}

This work is dedicated to men and women of our US Armed Forces and the American Farmer.

To those that fight to defend my freedom, I thank you. I have not taken the honor of serving in the military and I am ashamed to say that my views have been previously shaped by Hollywood and the media. Having now had the opportunity to witness your training, I can now say that I am humbled by your immense personal sacrifice to preserve my way of life. De Oppresso Liber.

I have spent the last 27 years pursuing a career in agriculture. Along the way I have had the pleasure of meeting some outstanding and brilliant individuals that support their families through agriculture. While each person has had their own story, they all shared in the same trials. The foundation of any great society is the ability to feed its people. 


\section{ACKNOWLEDGEMENTS}

The last four years have been the most trying, and humbling, time of my professional career. I have found it difficult at times to balance a job change, graduate program work, and family life. Although I count this work as a significant accomplishment, it will never be what I am most proud of. I frequently lose focus, but my priorities will always be my God, my wife, and my children.

I must first give glory to God for all that he has given me. I am thankful for his grace. In that he provided me a means of salvation through his son Jesus Christ. I may not have everything I want, but I have always had what I need. It is not the treasures of this earth, but the treasures we lay for ourselves in Heaven that have meaning.

My wife, Jessica, began this journey with me 20 years ago. She was with me through my Master's work. She allowed me to move her from one end of the country to other, only to come back to where it all started. She has provided me with three, unimaginably wonderful children. I cannot express the love and gratitude that I have for the way she has stayed by my side through all situations.

My children are the only thing I will leave in this life. Tylor, Olivia, and Baylee represent everything good that I call good. All three have the compassion, love, and work ethic that is disappearing in this world. I can only hope that they cling to their faith and are able to find the helpmeet that will support them in their journey. If I can leave them with one piece of advice, it is to never hunt for fame or fortune. If you seek God first, happiness will follow.

I would like to personally thank Jerry Yates for his assistance through my work. Jerry has been a valued advisor and friend. I thank you for your subject matter expertise and assistance with making connections to further my work. I also would like to thank Matt Davis, with the Texas Cattlefeeder's Association, for his assistance in collecting the data for my project. It is an understatement to say that this would not have been possible without his assistance.

Finally, I would like to thank my committee. Dr. Harry Boone, Dr. Deborah Boone, Dr. Matthew Wilson, and Dr. Alison Wilson. Although my interests have not precisely aligned with your own, I thank you for the guidance and support you have shown me through this process. 


\section{TABLE OF CONTENTS}

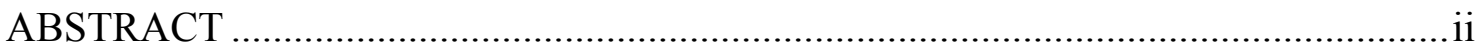

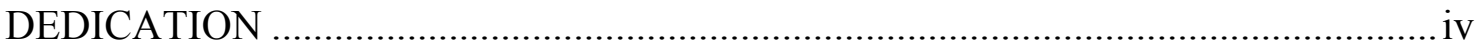

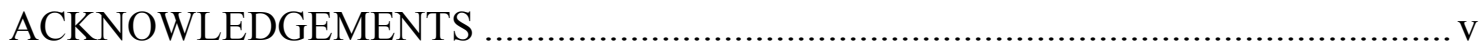

LIST OF TABLES ………................................................................................

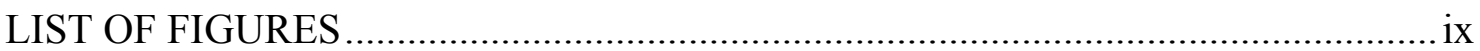

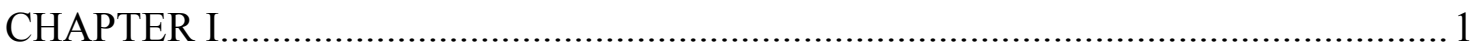

Special Forces Medical Sergeant/Special Operations Independent Duty

Corpsman Candidates: Large Animal Module ………………………....... 1

Purpose and Research Questions ............................................................. 3

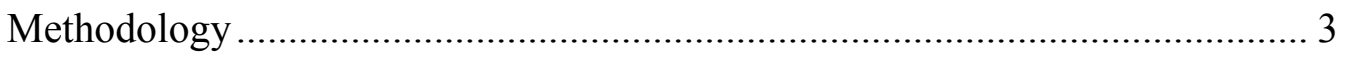

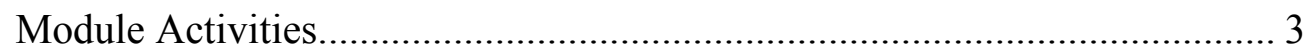

Data Collection and Analysis.................................................................... 5

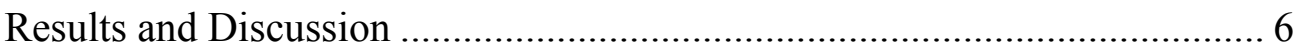

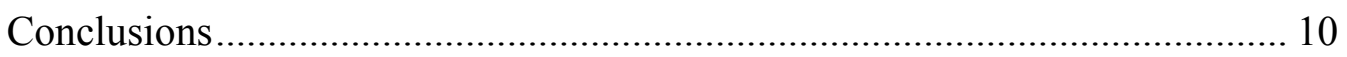

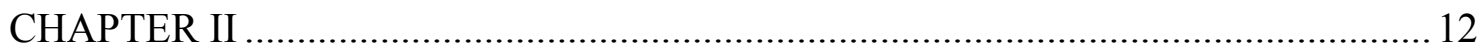

The Stockman's Scorecard Pilot Project: Establishing Validity and

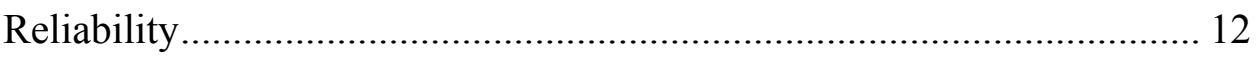

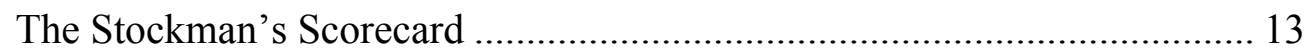

Willful acts of abuse …………………………….................................. 15

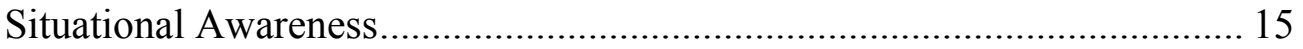


Herding Skill.

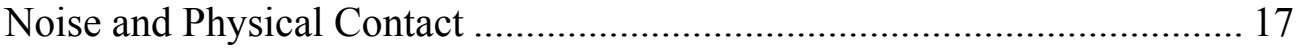

Determining Validity and Reliability.......................................................... 18

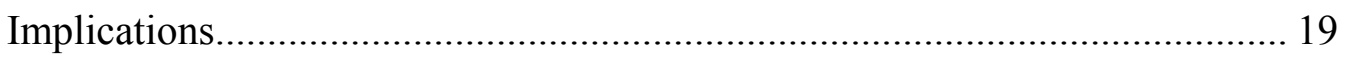

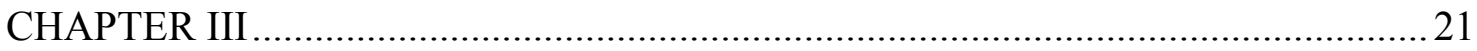

The Stockman's Scorecard: A Survey of Cattle Handling Practices .................. 21

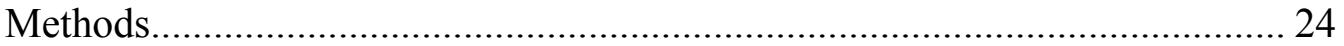

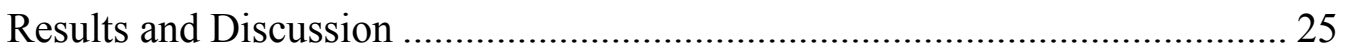

Quantitative Evaluation of Stockmanship ……………................................ 25

Qualitative Description of Stockman and Livestock Disposition.................. 32

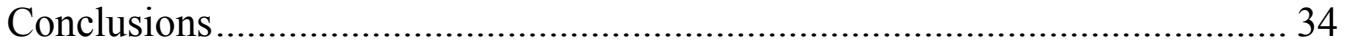

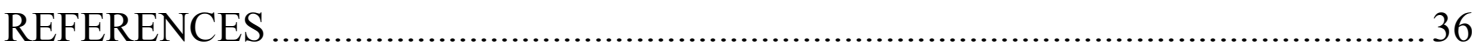

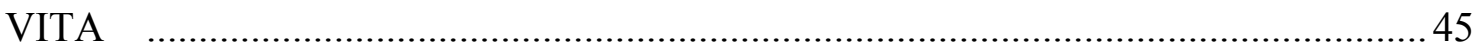




\section{LIST OF TABLES}

Table 1-1: Participant Demographics ........................................................................ 7

Table 1-2: Pre-Test vs. Post-Test Results..................................................................... 9

Table 3-1: Stockman's Scorecard Results ................................................................ 28

Table 3-2: BQA Feedyard Assessment Animal Observation Fails by Individual

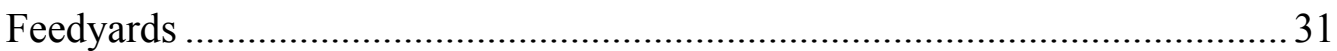

Table 3-3: Associations between the Scorecard and the BQA Feedyard Assessment ... 31

Table 3-4: Handler and Livestock Disposition........................................................ 32 


\section{LIST OF FIGURES}

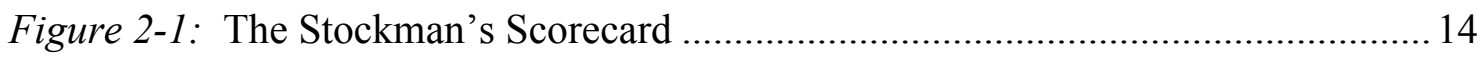

Figure 3-1: Individual Scores using the Stockman's Scorecard ...................................27 


\section{CHAPTER I}

\section{Special Forces Medical Sergeant/Special Operations Independent Duty Corpsman}

\section{Candidates: Large Animal Module}

The John F. Kennedy Special Warfare Center and School (JFK) at Fort Bragg, $\mathrm{NC}$ is the training/selection site for Special Operations Force (SOF) combat medics from all branches of the US military. The amount of training received at the school varies dependent on the branch of service. The programs offered at the school can be segmented into two main programs. The first Special Operations Combat Medics (SOCM) course spans 24 weeks of basic combat trauma training. This training includes: anatomy and physiology, the American College of Surgeons' Advanced Trauma Life Support (ATLS), pharmacology, and Emergency Medical Technician-Paramedic (EMTP) courses. The second phase of the program is the Advanced Special Operations Combat Medics (ADSOCM) course. This course provides: advanced anatomy and physiology, pharmacology, infectious disease, and trauma care.

Once deployed, the medics are expected to maintain a high level of physical preparedness and are continuously training and conducting operational exercises. SOF Combat Medics may be utilized in a variety of missions, such as: civil affairs, combatting terrorism, direct action, foreign enternal defense, humanitarian assistance, and operations other than war. When not actively involved in preparing or conducting a mission, the medics are responsible for Force Health Protection (Butler, 2002; Butler \& Beading, 2014). In deployment situations, they are trained to provide medical care independent of specialists. It is advantageous for Special Forces Operators to utilize their skills to develop rapport with indigenous populations they encounter while on mission. 
Establishment of open, trustworthy, lines of communication, allows the teams to foster relationships which can increase safety and the likelihood of a successful mission outcome. The medical component of these teams are best suited to fulfill this role. Although their training is focused on insuring the wellbeing of their team, their skills are transferable to providing medical assistance to local populations.

West Virginia University Health Sciences Center (WVU-HSC) hosts small groups of US Army Special Forces Medical Sergeants (SFMS) and US Navy Special Operations Independent Duty Corpsman (SOIDC) candidates for a four-week applied medical experience program. While at WVU-HSC, the candidates rotate through various departments practicing skills acquired throughout their training. Following completion of their program, and acceptance as an active Special Operations Combat Medic, the servicemen will function as the medical component of small Special Operations teams around the globe. Although WVU is one of many locations that provide the applied experience opportunity, it is the only institution that is currently providing additional training in animal husbandry and veterinary medicine.

In many of these communities, livestock play an essential role in the social, political, and cultural fabric of their lives. The medical care provided to the local population, is deemed critical to "gaining the hearts and minds" of indigenous peoples (Hughes \& Hughes, 2009). Penner (2011) points out that "In regions where livestock represent nearly the entire economy for a family or an entire tribe, veterinary care is a highly effective means to gain access to an area" (p. 49). While the training of SFMS and SOIDC candidates does incorporate a veterinary component, this is centered on canine 
and equine care. The diverse backgrounds of the candidate pool limits possibility of future Operators having experience in food animal production.

\section{Purpose and Research Questions}

The WVU Large Animal Module provides the participants with foundational information on animal handling, husbandry, and veterinary medicine. Hughes and Hughes (2009) recommended that pre-deployment veterinary training may "prove critical to the advancement of combat medic in-theater skill sets" (p. 18). It is assumed that with the high skill level of Special Forces Combat Medics, a basic livestock program, which includes: animal behavior, animal husbandry practices, and veterinary skills that easily relate to human medical principles will provide valuable skills for these soldiers to develop rapport with indigenous populations.

The educational objectives for the module are:

1. To provide foundational understanding of the relationship between animal instincts and observed behaviors.

2. Introduce participants to unfamiliar livestock species.

3. Develop skills to effectively move livestock.

4. Provide understanding of common livestock husbandry practices.

5. Establish a link between human medical training and veterinary practices.

The study questions we seek to answer are:

1. What base knowledge, concerning livestock handling and husbandry, do SFMS/SOIDC candidates possess?

2. Although some veterinary medical topics are covered during their previous training, would a more in-depth program be of benefit to SFMS/SOIDC medics?

\section{Methodology}

\section{Module Activities}

The 10-hour educational module is conducted over a 1.5-day period at WVU

Reymann Memorial Farms. A one-hour lecture to discuss animal behavior and the 
concept of low-stress animal handling begins the program. Key points covered in lowstress handling include: factors that contribute to a fear response in livestock, the physiological characteristics of how animals see and hear; utilization of an animal's flight zone and point of balance in herding practices, recognition of animal temperament, handler behavior and movement during the herding process, and the use of driving aids when herding livestock. A second presentation, discussing dystocia, covers: monitoring the birthing process, factors contributing to dystocia, and methods for correcting malpresentation in the different livestock species.

The remainder of the program offers a variety of hands-on activities with beef cattle, poultry, sheep, and swine. Groups are rotated through stations for each species, and a similar informational format is used at each station. Each station covers: prominent behavioral characteristics, production cycles, common husbandry practices, physical restraint, and the diagnosis and treatment of common adverse health conditions. Specifically, the activities included: use of a hog board and snare for restraining swine, flipping sheep and hoof trimming, rectal palpation of beef cattle, casting large livestock, proper restraint of poultry, techniques and anatomical locations for collecting blood samples, body weight estimation, body condition scoring, and procedures for health examinations. Veterinary staff lead a discussion with the group on antibiotic selection and formulary differences between human and veterinary medical pharmaceuticals. The final activity allowed the participants to demonstrate their understanding of herding principles. Each participant was placed in a pen of yearling bulls, and asked to separate one member from the herd and hold him at the opposite end of the pen. All animal activities were approved by the WVU IACUC (protocol \# 1604002146). 


\section{Data Collection and Analysis}

To answer our evaluation questions, a quasi-experimental design, utilizing pretest and post-test instruments, was used (Ary, Jacobs, Sorensen, \& Walker, 2012). In non-randomized designs, selection bias is a realistic threat to internal validity. For this study the rigorous selection and training process of the experimental and control group members, along with the administration of the same pre-test instrument, establish uniformity of the groups. The pre-test and post-test were constructed by the researcher to target expected knowledge gain from completion of the 1.5 day program. The pre-test utilized both multiple choice and short-answer questions. The post-test asked the same questions as the pre-test and included demographic questions related to the attendee. Validity of the instruments was established through review of the materials by the members of the educational team that presented the course content. Reliability of the testing instruments were determined by a split-half analysis using SPSS (Ver. 25). The inter-item correlation for the pre-test produced a Spearman-Brown Coefficient of 0.762 and the post-test's coefficient was 0.946 . The instruments' standard of reliability can be interpreted as exemplary (Robinson, Shaver, \& Wrightsman, 1991). Approval for participant evaluation was provided by the WVU IRB (IRB Protocol \# 1801950697).

Candidates are assigned to institutions for the applied medical experience program by JFK leadership. Those that are assigned to WVU are considered the treatment group and those assigned to other locations serve as the control. For this evaluation, the research team was allowed contact to those that received training at other institutions through JFK leadership. The evaluation instruments were provided to both groups using Qualtrics. Links to the Qualtrics pre-test, a cover letter, and all supporting 
documentation were sent via email to JFK training center command, who forwarded the message to both participant groups one week prior to conducting the training. Only those tests that were completed prior to initiation of the program were included in the data set. Immediately following the program, a second message was forwarded from the JFK training center command, to both groups, containing the post-test link, cover letter, and supporting documentation. The participants had one week from the email being sent to complete the evaluation, and only those received prior to the deadline were considered for analysis.

The pre-test and post-test were scored following the completion of the post-test. All tests were scored by the same individual and completed within one day. The scoring was based on the number of correct responses. Individual results were entered into an Excel spreadsheet and imported in JMP for further analysis. Demographic data was analyzed to report frequencies and pre-test/post-test score differences were analyzed using the Match pairs function of JMP (Ver. 14). Significance was determined at $\alpha=.05$, set a priori.

\section{Results and Discussion}

Eleven of the classes that have attended training at WVU were used in the dataset. These groups provided 66 participants. The control groups came from two classes and provided 46 participants that were assigned to other institutions. The demographic breakdown for all subjects is provided in table 1. The US military attracts servicemen from all backgrounds. We asked the participants to classify their hometown by size. Their choices were: Large City/Metropolitan Area (21 \%), Suburban (25\%), Small Town $(23 \%)$, or Rural town $(30 \%)$. Even though the largest percent came from a rural 
community, few of the participants have had previous exposure to livestock species. Sixty-six percent $(n=44)$ of the treatment group had no previous exposure to food animal species and 86 percent $(n=40)$ of the control group indicated no previous experience. Of those that had previous livestock experience, much of that exposure was with horses $($ Treatment $=16$, Control $=4)$. The lack of previous livestock experience is also reflected by participants having been involved with 4-H and/or FFA programs in their youth. Ninety-two percent of the treatment group $(n=61)$ and 97 percent $(n=8)$ of the control group had never participated in a 4-H and/or FFA program.

Table 1-1

Participant Demographics

\begin{tabular}{|c|c|c|}
\hline Hometown Size & $N$ & $\%$ \\
\hline Large City/Metro & 24 & 21 \\
\hline Suburban & 28 & 25 \\
\hline Small Town & 26 & 23 \\
\hline Rural & 34 & 30 \\
\hline \multicolumn{3}{|l|}{ Previous Livestock Experience } \\
\hline None & 84 & 75 \\
\hline Cattle & 12 & 11 \\
\hline Equine & 20 & 18 \\
\hline Poultry & 15 & 13 \\
\hline Sheep/Goats & 5 & 4 \\
\hline Swine & 6 & 5 \\
\hline Youth Livestock Participation & Yes & No \\
\hline 4-H/FFA & 9 & 103 \\
\hline
\end{tabular}


There has been minimal research to assess the general public's knowledge of practices. A 1993 pilot study by Birkenholz (1993) assessed the agricultural literacy of 2005 adults and teenagers in Illinois, Michigan, and Missouri. Agricultural Literacy was gaged on knowledge of: the significance of agriculture in America, agriculture policy, how agriculture related to natural resources, basis agricultural production practices for plants and animals, processing of agricultural goods, and marketing and distribution of commodities. Although the author acknowledged that the small sample size made it impossible to make inference to the entire US population, he did offer generalization that support the premise. Adults had a greater agricultural literacy than the youth. Literacy was higher for rural residents compared to urban, and small-town residents had a greater literacy over their large city counterparts. Similar results were seen in a 2013 study of elementary students in Houston, TX (Luckey, Murphrey, Cummins, \& Edwards, 2013) Thirty percent of the students claimed to have no knowledge of agriculture.

There were 46 possible correct responses on the testing instruments used for this evaluation. There was no significant difference for pre-test scores between those that had attended the training (17.2 correct response) and the control group (13.8 correct responses)(see Table 1-1). Some basic knowledge was expected. The medical training program at JFK utilizes live tissue models. All participants, having advanced to the applied clinical experience, had acquired previous knowledge of average body temperatures and locations for collection of blood samples for the different species. They were also able to deduce, through common sense, some situations where an animal may behave abnormally. These would be when an animal is sick or injured. 
Table 1-2

Pre-Test vs. Post-Test Results

\begin{tabular}{|c|c|c|c|c|}
\hline Group \# & $\mathrm{N}$ & Pre-Test & Post-Test & Difference \\
\hline 1 & 6 & 20.3 & 38.5 & $+18.2 *$ \\
\hline 2 & 6 & 17.5 & 35.8 & $+18.3^{*}$ \\
\hline 3 & 6 & 18.8 & 35.6 & $+16.8^{*}$ \\
\hline 4 & 6 & 15.2 & 35.2 & $+20.0 *$ \\
\hline 5 & 6 & 13.5 & 35.5 & $+22.0 *$ \\
\hline 6 & 8 & 18.5 & 36.9 & $+18.4 *$ \\
\hline 7 & 6 & 13.8 & 36.8 & $+23.0 *$ \\
\hline 8 & 6 & 15.0 & 36.5 & $+21.5^{*}$ \\
\hline 9 & 6 & 18.0 & 43.2 & $+25.2 *$ \\
\hline 10 & 6 & 18.3 & 34.3 & $+16.0 *$ \\
\hline Control & 34 & 17.9 & 19.1 & +1.2 \\
\hline 11 & 4 & 22 & 33.3 & $+11.3 *$ \\
\hline Control & 12 & 15.7 & 11.9 & -3.8 \\
\hline Treatment Average & 66 & 17.2 & 35.7 & $+18.5^{*}$ \\
\hline Control Average & 46 & 13.8 & 14.7 & +0.9 \\
\hline
\end{tabular}

* Significant at $\alpha=0.05, p<0.0001$

There was a significant difference in change from pre-test to post-test scores for those that had completed the livestock module at WVU (Treatment $=+18.5$ vs. Control $=$ $+0.9, \mathrm{p}<.0001)$. The treatment group averaged 35.7 correct responses on the post-test while there was a negligible increase in the number of correct responses for the control group (ave $=14.7)$. Those participants that were able to attend the training were able to 
understand the observed behaviors of livestock and temperaments associated with the behaviors. They were able to describe how to properly herd the different livestock species and methods to safely retrain livestock for either diagnosis or performance of a veterinary health procedure.

\section{Conclusions}

For the majority of those that participated, this was their first significant interaction with livestock of any kind. The training program at the JFK Special Warfare Center and School utilizes livestock as a model to acquire human medical skills, and the ability to provide basic care of limited livestock species. It cannot be overstated that the primary role of the combat medic is to insure the wellbeing of US military personnel and their assets. Human health will always take the priority over animals. During Operation Enduring Freedom (Hughes \& Hughes, 2009), of all the service provided by combat medics, only $0.4 \%$ was procedures on livestock. The type of mission will dictate the resources made available. In purely humanitarian efforts, the medics may be accompanied by subject matter experts (veterinarians, physicians, agronomist, etc.) to provide care and education to the local population (Rufolo \& Facciolla, 2011), but this is not the norm.

Observation of the participants during the module, indicated the start of a learning process. The veterinary medicine component was quickly grasped by the medics. The physiological similarity of human and other mammals allowed the participants to translate their knowledge of human medical practices to veterinary procedures. However, it was the experiences of restraining and herding the different species that may prove most valuable to these medics once deployed. They have begun to gain 
competencies that will allow them an additional avenue to foster relationships.

Kristjanson (2010) states that, "Livestock are seen within the greater context of peoples' livelihood strategies, accounting for the fact that the resource-poor have more pressing concerns than raising the productivity of their livestock enterprises" (p. 37). He goes on to explain that livestock are more than just a source of food, but provide valuable manure for fertilizer, draught power for everyday chores, and help maintain social capital and status within a community. Efforts to improve the productivity of livestock production, which ignore the social ramifications, have the potential to disrupt normal life in these communities (Riethmuller, 2003). Subsidized agriculture may be in norm in developed societies, but low-income producers prioritize food security and a desire to maintain their lifestyles (Preston, 1995).

This evaluation only focused on the acquisition of knowledge from participation in the program. Instructors were able to observe the medics apply this knowledge to successfully herd the different species. The future application of these skills has not been evaluated. The participants have not been followed into active duty to determine if they have been able to apply those skills in a real-life situation. There has been antidotal evidence that opportunities have arisen in post-module training exercises where the participants have been able to apply the training. 


\section{CHAPTER II}

\section{The Stockman's Scorecard Pilot Project: Establishing Validity and Reliability}

The livestock industry has been proactive in assessing the care of livestock at the farm and processing levels through facility evaluations such as the BQA Feedyard Assessment (BQA.org, 2016), The North American Meat Institute Audit (Grandin, 2017), and the European Welfare Quality Audit ${ }^{\circledR}$ (Welfare Quality, 2009). As general themes, the assessments seek to discover if appropriate management protocols are in place to insure the implementation of scientifically based, industry recognized, Best Management Practices. Auditors also seek to evaluate animal-based measurements, such as: if the livestock are clean, do they have an acceptable body condition score, are skin lesions or abrasions present, and do they appear to be comfortable while in their housing area. Cattle behavior based measurements are used to evaluate livestock handling capabilities. The number of animals that slip, fall, or vocalize while being moved to the processing area or through a handling system identify, if the animal has experienced stress during the handling event.

The argument has been made that the human factor may strongly influence audit results (Rocha, Velarde, Dalmav, Saucier, \& Faucitano, 2016). Proper animal handling practices and correct facility design contribute to a positive human-animal interaction (Lima, Negrao, Paz, \& Grandin, 2016). Coleman and Hemsworth (2014) is quoted as saying, "While welfare monitoring schemes are likely to improve animal welfare, the impact of such schemes will only be realized by recognizing the limitations of stockpeople, monitoring stockmanship and providing specific stockpersons training to target key aspects of stockmanship" (p. 137). Gonyou (1995) stated "The potential of 
well-designed facilities and equipment will only be realized if the stockpersons use them properly" (p. 74). Grignard et al. (2001) says, "Despite the complexity of handling situations, it is likely that the human factor represents the most important parameters of such situations and so needs to be precisely defined" (p. 276).

How do we evaluate the human component of the human-livestock interaction?

The Stockman's Scorecard has been designed to assign a numerical score to the stockmanship abilities of cattle handlers. The objectives of this pilot study are to:

1. Establish the validity and reliability of the evaluation instrument.

2. Determine the intra-rater reliability for multiple observers evaluating the same individual.

\section{The Stockman's Scorecard}

The instrument (see Figure 2-1) is divided into three distinct skill sections (situational awareness, herding skill, noise/physical contact) based on common themes identified in published research (Grandin, 2008). For each skill, stockman actions have been identified that can be interpreted as producing a positive animal handling outcome (no points deducted), a minor fault action (minus 5 points) that may be negative or have no affect the activity outcome, or a major fault action (minus 10 points) that highlight actions that have proven to be detrimental to producing a positive animal handling outcome. 


\begin{tabular}{|c|c|}
\hline \multicolumn{2}{|r|}{ Incidence of Abuse (Automatic re-education) } \\
\hline & $\begin{array}{l}\text { - Intentionally slams gates into animals } \\
\text { - Extreme physical contact (hands/feet/driving aid) } \\
\text { - } \\
\text { - Intentional contact with sensitive areas (genitals, } \\
\text { anus, eyes, etc.) } \\
\text { - Constant/unnecessary use of electric prod }\end{array}$ \\
\hline 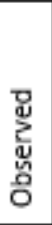 & $\begin{array}{l}\text { Handler Disposition: } \\
\text { Livestock Temperament: } \\
\text { Years worked at Yard: } \\
\text { Years worked with cattle: }\end{array}$ \\
\hline & Situational Awareness \\
\hline & Valued team contributor \\
\hline & Operates independent of team $(-10)$ \\
\hline & Ineffective team member $(-5)$ \\
\hline & Fills crowd pen $1 / 2$ full or less \\
\hline & Overfills crowd tub $(-10)$ \\
\hline & Fills crowd pen over $1 / 2$ full $(-5)$ \\
\hline & Regulates animals through pinch point \\
\hline & Forces animals through pinch point $(-10)$ \\
\hline & Fails to regulate flow through pinch point $(-5)$ \\
\hline & Avoids blind spot unless necessary \\
\hline & Continually works in blind spot $(-10)$ \\
\hline & Unintentionally works in blind spot $(-5)$ \\
\hline & Fails to open/close gates $(-5)$ \\
\hline & Herding Skills \\
\hline & Demonstrates understanding of Point of Bal. \\
\hline & No understanding of point of balance $(-10)$ \\
\hline & Stands in front of animal and taps rear (-5) \\
\hline & Effectively uses Flight Zone Pressure \\
\hline & Excessive flight zone pressure $(-10)$ \\
\hline & Slow to add/remove flight zone pressure $(-5)$ \\
\hline & Unable to move group as unit $(-5)$ \\
\hline & Noise/Physical Contact \\
\hline & Uses appropriate amount of noise \\
\hline & Intentionally generates metallic noise $(-10)$ \\
\hline & Constant/unnecessary screaming/yelling $(-10)$ \\
\hline & Unnecessary noise $(-5)$ \\
\hline & Uses driving aid appropriately \\
\hline & Electric Prod as primary driving aid $(-10)$ \\
\hline & Electric prod applied at wrong time $(-5)$ \\
\hline & Uses appropriate physical contact \\
\hline & Excessive/Unnecessary Physical Contact $(-10)$ \\
\hline & Tail twisting after animal movement $(-5)$ \\
\hline
\end{tabular}

Figure 2-1: The Stockman's Scorecard 


\section{Willful Acts of Abuse}

The first group of criteria, that are not part of the formal scoring process, are labeled "Incidence of Abuse." At any time, if an act of willful animal abuse is observed, the evaluator must rely on his/her best judgement to determine if an evaluation should continue, or if the incident should be immediately addressed. The bulleted points provided in the box are key observations that can be perceived as abuse which we want to eliminate from our industry. If observed, it is the author's opinion that all evaluation activities should stop and immediate corrective action implemented. An act of willful abuse should result in a failed evaluation.

\section{Situational Awareness}

The situational awareness theme contains a group of actions intended to identify the handler's ability to see the big picture of the animal handling activity. Can the individual understand the environment/facility design within which the activity is taking place, evaluate the temperament of the cattle that are being handled, and work effectively as a member of a team to complete the assigned task? An observer is asked to evaluate the subject's ability to:

- Teamwork: How well does the individual work as part of the team? Do they take direction from others, or do their own thing which hinders the efficiency of the activity?

o Minus 10 Example: Are they given instructions during the animal movement, but ignore the instruction? Are they constantly in the wrong place hindering the activity? Do they appear to "take offense" to being given instructions from other handlers?

o Minus 5 Example: Do they take direction, but appear to be inexperienced and not know where to position themselves? Are they sometimes in the wrong place?

o Positive Example: Do they take direction, and provide direction as a team member? Do they consistently position themselves to fulfill their role in the activity? 
- Overcrowding: Concerns the effectiveness in moving animals through a pinch point, such as a gate opening or the entrance into the alley leading to the chute.

o Minus 10 Example: Do they try to force a large group of animals out of the gate causing a "pile up"? Do they over fill the tub, leading to the chute, causing the animals to pile up and continue to apply pressure?

o Minus 5 Example: They unintentionally cause animals to pile up at the gate opening, or over fill the tub leading to the chute, but do not continue to apply pressure and allow the animals to sort it out.

o Positive Example: They position themselves, or direct someone to position themselves, at the gate opening to regulate the flow of cattle through the gate. They only fill the tub half full and patiently allow the cattle to enter the alley way.

- Blind Spot: Does the handler understand the concept, or location, of an animal's blind spot.

o Minus 10 Example: The handler immediately approaches an unaware animal in the blind spot. Handler attempts to stay in the animal's blind spot. Handler may be kicked multiple times.

o Minus 5 Example: The handler, unknowingly, enter blind spot but doesn't repeat mistake. May be kicked.

o Positive Example: The handler makes the animal aware of their presence before entering the blind spot. Only works in blind spot when necessary. Works to stay out of blind spot as they are moving the animals.

\section{Herding Skill}

The herding skill theme evaluates the handler's understanding of cattle behavior and physiology as it relates to herding and animal movement. Can the subject effectively move cattle? The observer is asked to evaluate the subjects' ability to utilize the animal's:

- Flight Zone: Evaluates the handlers understanding of the principle for initiating and stopping animal movement.

o Minus 10 Example: The handler constantly penetrates too deep into an animal's, or into the group of cattle's, flight zone causing animals to turn in the wrong direction. Or are they unwilling to apply sufficient pressure to encourage cattle to move in the desired direction?

0 Minus 5 Example: Handler works on the edge of the flight zone, but fails to take proper action if an animal, or animals, break away from the group. Example: an animal breaks away from group and the handler spends unneeded time to try and bring them back into the group.

o Positive Example: Handler works edge of flight zone. Moves into and out of flight zone to encourage animals to move at their own pace. Allows animals that break away to rejoin group on their own. 
- Point of Balance: Does the handler understand the application of the point of balance concept.

o Minus 10 Example: When moving animals in an alleyway, they constantly stand behind the animals and does not utilize a technique where they walk opposite the flow of animals to take advantage of point of balance and escape instincts to encourage animals to continue moving in alleyway.

o Minus 5 Example: When in the alleyway leading to the chute, or in another confined space, the handler stands in front of the point of balance and taps the animal on the rump in an attempt to make it move forward.

o Positive example: Handler is able to turn animal in any direction desired. When in an alleyway, the handler walks alongside the cattle in the opposite direction of animal movement to take advantage of escape instinct and point of balance.

\section{Noise and Physical Contact}

The noise and physical contact theme evaluates the stockman's use of noise and physical contact to move livestock. How effective is the handler at using noise as a tool to assist with moving livestock? Does the handler understand how to effectively use a driving aid in a productive manner? If physical contact is necessary, is the handler able to demonstrate a calm/gentle approach to its application? The observer evaluates the subject's use of:

- Human Vocalization: While vocalization is frequently required to move animals, does the handler use the proper amount and volume of noise?

o Minus 10 Example: The handler yells at the "top of their voice" during the entire animal handling activity, even when animals are moving in the desired direction. The amount of yelling is interpreted as abusive and is forcing animals to move at a faster than normal pace.

- Minus 5 Example: The handler constantly used vocal cues while animals are moving in the desired direction. Vocal noises are low volume, but unnecessarily consistent and causes animals to move at a faster than normal pace.

o Positive Example: Vocalization is only used as a means to gain animals attention. Once animals are moving in the desired direction, vocalization stops. Doesn't use vocalization to scare animals. 
- Artificial Noise: This evaluates the handler's use of artificial noise (banging driving aids on facility, slamming gates, horns on motorized vehicles) to move livestock.

o Minus 10 Example: The handler constantly, and potentially violently, bangs driving aids on facility components. Slams gates open/closed to create a metallic sound to frighten livestock. Constantly blows horn on motorized vehicle to frighten animals. Forces animals to run.

o Minus 5 Example: Unnecessarily uses driving aid to generate non-metallic noise which causes animals to move at a faster than normal pace.

o Positive Example: Only uses artificial noise to gain animal's attention. Avoids creating metallic noise.

- Physical Contact: This category gauges the handler's ability to control their temper during animal handling.

o Minus 10 Example: Electric prod is the primary driving aid. Frequently shocks animals without trying another movement technique. Uses excessive physical contact in attempts to make stationary animal move (hitting, kicking). Slams gates into animals. Over aggressive tail twisting that could result in breaking tail.

o Minus 5 Example: Forceful contact with animal, but only observed once. Twists tail on animal (not overly aggressive) but does not release twist when animal begins to move. Uses electric prod sparingly but applies at wrong time.

o Positive Example: Electric prod only used as tool of last resort. Releases tail twist when animal moves. Gentle pats to encourage animal movement. Observed stroking stationary animals on back or sides as a means to calm.

\section{Determining Validity and Reliability}

In order to produce a usable evaluation instrument, one must establish that it is a valid and reliable tool to measure the underlying construct. Validity refers to the accuracy of the instrument. The concept answers the question, does the instrument measure the construct it is intended to measure. The related term of reliability provides assurance that the measurement consistently collects the desired data. If we compare validity and reliability to shooting a gun, validity asks if we are hitting the "bullseye" and reliability asks if we are hitting the same point on the target with each shot. If the instrument is both valid and reliable, we will be hitting the bullseye with each shot. 
Content and face validity of the scorecard were established by a panel of experts (Huck, 2012). During the conception phase, the card was provided to four recognized experts in cattle handling and behavior, who agreed that the content of the card included all items that one would wish to observe when evaluating a cattle stockman. The instrument's internal consistency, or reliability, was determined by pilot testing at three Midwest cattle feeding facilities. Observer volunteers were trained on the use of the scorecard and evaluated 19 separate stockmen. A split-half analysis was conducted using SPSS (v 25) to calculate a Spearman-Brown coefficient of individual final scores (Carmines \& Zeller, 1979). The instrument constructs were found to be exemplary with a coefficient of 0.76 exceeding the threshold of 0.30 for inter-item correlations (Robinson, Shaver, \& Wrightsman, 1991).

To determine if multiple observers could use the scorecard to score an individual stockman in a similar manner, three observers were shown six videos of individuals moving a group of steers from their home pen to the working chute. The observers scored each handler using the scorecard and final scores were used to calculate an intraclass correlation coefficient (ICC) using SPSS (v 25) (Hallgren, 2012). The observers exhibited a high level of agreement with an ICC $=0.66$ which can be classified as good intra-rater reliability (Cicchetti, 1994).

\section{Implications}

Grandin (2014) has stated that "people manage the things they measure" (p. 462). She goes on to say, "Measurement is essential because it enables management to determine if procedures are improving or getting worse" (p. 462). It has been established that the Stockman's Scorecard is a valid, reliable, instrument that can be used to assign a 
numerical score to the actions of cattle handlers. The application of this tool are varied. Extension educators, and stockmanship trainers, can use the instrument in a pre-test/posttest format to determine the effectiveness of their stockmanship training. Facility managers may use the scorecard as a means to evaluate their employees and identify targeted training needs to improve abilities. Furthermore, the tool may serve as a complement to current assessment procedures to evaluate the human factors associated with positive animal welfare efforts.

Although the scorecard has been determined to be valid and reliable, further work is needed to establish its efficacy. Studies have been planned to use the card in commercial cattle feedlots to see if there is a relationship between final scores and animal behavior observations recorded from the BQA Feedyard Assessment. The authors additionally wish to establish what constitutes an acceptable final score for an individual being observed. 


\section{CHAPTER III}

\section{The Stockman's Scorecard: A Survey of Cattle Handling Practices}

The behavior and actions of stockmen has a direct effect on the behavior and welfare of livestock (Zulkifli, 2013). The result of this human-livestock interaction is dependent on the attitudes and behavior of the stockperson (Waiblinger, Menke, \& Coleman, 2002). Behavioral research in beef cattle (Petherick, Doogan, Holroyd, Olsson, \& Venus, 2009a; Probst, Hillmann, Leiber, Kreuzer, \& Neff, 2013), dairy cattle (Rushen, Munksgaard, Passille, Jensen, \& Thodberg, 1998; Waiblinger, Menke, \& Folsch, 2003), and swine (Tallet et al., 2014) has shown that an animal's response is dependent on the quality of treatment received from their human handlers. In dairy cattle (Munksgaard, Passille, Rushen, Thodberg, \& Jensen, 1997; Passille, Rushen, Ladewig, \& Petherick, 1996), beef cattle (Boivin, Garel, Mante, \& Neindre, 1998), and sheep (Boivin, Nowak, Despres, Tournadre, \& Neindre, 1997), there is support that livestock may be able to differentiate between handlers based on their familiarity with the stockman and the quality of the stockperson's handling. Also, it has been shown in pigs that the group behavior was altered when a single pen mate was subjected to negative handling practices although the others of the group did not receive the treatment (Reimert, Fong, Rodenburg, \& Bolhuis, 2017). Beef cattle will habituate to common handling practices and human contact by frequent exposure (Maston, 2006), especially at a younger age (Etim, Offiong, Udo, Williams, \& Evans, 2013; Fukasawa, 2012). However, cattle will not habituate to painful procedures and adverse handling practices (Grandin, Oldfield, \& Boyd, 1998). 
Livestock handling involves both the restraint of animals, and encouraging a desired movement, in a way that minimizes fearful reactions (Gonyou, 1995). The majority of our knowledge, and specific recommendations, of how to handle livestock have come from Dr. Temple Grandin. Her work emphasizes that the stockman should be calm, quiet, slow, and deliberate when working animals (Grandin, 2015, p. 65-95). Stockmen need to understand the behaviors of cattle, and their physiology, in order to take advantage of their natural prey instinct when herding (Grandin \& Deesing, 2008). Evaluation of stockmanship is a critical component in assuring positive animal welfare (Grandin, 2014; Grandin, 2001). Assessments of stockmanship involves the observation of animal behaviors and quantitative measurements of their temperament. Chute scoring, chute exit speed scoring, vocalization tests, and aversion tests are all measures to evaluate the overall treatment of cattle (Grandin \& Shively, 2015; Grandin, 1994). The livestock industry has been proactive in assessing the care of livestock at the farm and processing levels through facility evaluations such as the BQA Feedyard Assessment (BQA.org, n.d), The North American Meat Institute Audit (2013), and the European Welfare Quality Audit $^{\circledR}$ (Welfare Quality Network, 2009). As general themes, the assessments seek to discover if appropriate management protocols are in place to insure the implementation of scientifically based, industry recognized, Best Management Practices. Within these evaluations, highly reliable, animal-based measurements are utilized to determine the quality of stockmanship (Grandin, 2015). Specifically, the BQA Feedyard Audit askes that 100 head of cattle be observed to determine the number of cattle that: are touched with an electric prod, fall upon release from the chute, stumble/trip when released from 
the chute, vocalize in chute before procedures, jump or run when released from the chute, or miscaught and not readjusted while in the chute.

While these measurements are appropriate to assess improvements in stockmanship within an operation (Rushen \& Passille, 2015), how are we to determine what stockperson actions caused any aberrations identified in these animal observations? The argument has been made that the human factor may strongly influence audit results (Rocha, Velarde, Dalmav, Saucier, \& Faucitano, 2016). Coleman and Hemsworth (2014) are quoted as saying, "While welfare monitoring schemes are likely to improve animal welfare, the impact of such schemes will only be realized by recognizing the limitations of stockpeople, monitoring stockmanship and providing specific stockpersons training to target key aspects of stockmanship" (p. 137). Gonyou (1995) stated "The most important part of a livestock handling system are the persons who handle the animals and operate the facilities and equipment" (p. 74). He goes on to say, "the potential of well-designed facilities and equipment will only be realized if the stockpersons use them properly" ( $p$. 74).

The Stockman's Scorecard is a novel evaluation instrument designed to measure the quality of beef cattle stockmanship. The scorecard has previously been proven to be a valid and reliable tool for assigning a numerical score to the stockmanship abilities of cattle handlers. The card places a value on negative handling actions, which have been identified from other published works. Each stockman begins an evaluation with 100 points. The observer deducts the specified points for each negative action performed by the subject. At the end of the evaluation, the total deductions are determined and subtracted from 100 to establish a final score. The purpose of this paper is to: 1) 
document the initial use of the scorecard in a feedlot setting, and 2) provide further support to its validity by establishing an association with other quantitative and qualitative means of evaluating stockmanship.

\section{Methods}

Volunteer observers were recruited to preform data collection. The volunteers were all considered experts in cattle handling and frequently conducted $B Q \mathrm{~A}^{\circledR}$ Feedyard Assessments. The observers were provided with an observation instrument that included the Stockman's Scorecard and the animal-based observations recording component of the BQA ${ }^{\circledR}$ Feedyard Assessment. Prior to any data collection the observers were provided a narrated PowerPoint presentation that detailed the methodology of the scorecard and its use. Once the materials had been reviewed, a conference call was held with the primary researcher and the observers to explain the intent of the evaluation, the desired data to be collected, and to answer any questions or provide clarity on the methodology and use of the card.

Data collection occurred over the period of one year (March 2018 to April 2019). The observers were asked to evaluate one to two employees at each facility using the scorecard as they were conducting a normally scheduled BQA Feedyard Assessment. The observers evaluated each subject using the scorecard criteria and collected the animal observation data on a maximum of 100 head through the handling system. Immediately following data collection, the observer was asked to use their own words to describe the disposition of the cattle and the stockman. For a stockman they could use words such as calm, angry, hurried, or nervous. For the cattle they could use words such as calm, stubborn, flighty, or riled up. 
Completed scorecards were scanned by computer and stored as PDF files to be emailed to the researcher. Once received, the individual scorecard results were entered into an Excel spreadsheet. The data for each observation point was recorded as a "zero" or a "1". If an action, on the part of the stockman, was observed, it was recorded as a “1”. All unobserved observation points were recorded as a "zero." Frequencies and standard deviations were determined by analysis with Microsoft Excel. Spearman's Rho Correlation to determine associations between the Scorecard and BQA Feedyard Assessment results were performed with JMP (ver. 25). For the Spearman's Correlation analysis, a Benjamini-Hochberg adjustment was used with a 10 percent false discovery rate used in the calculation. The handler and livestock disposition determinations were qualitatively evaluated by the researcher and condensed into themes. The themes were then coded to create a disposition scale. For the stockman scale: $1=$ calm/quiet, $2=$ calm plus another descriptor, $3=$ fast/rushed/Excited, $4=$ nervous/unsure/frustrated. The coding for the livestock scale was: $1=$ calm/quiet, $2=$ slightly jumpy, $3=$ excited/jumpy/wound-up, $4=$ stubborn/hesitant. For analysis, codes were combined to create a nominal variable scale (handler, $1=$ calm/quiet, $0=$ other descriptor; livestock, 1 $=$ calm/quiet, $0=$ other descriptor) and Kappa was calculated with JMP (ver. 25) to determine level of agreement between Scorecard score and the handler and livestock disposition scales. Statistical significance was set $a$ priori at $\alpha=0.05$.

\section{Results and Discussion}

\section{Quantitative Evaluation of Stockmanship}

The intent of this paper is to demonstrate the application of the Stockman's Scorecard in a feedlot setting, and to further validate it as a tool for measuring the quality 
of beef cattle stockmanship by determining if associations exist between an individual livestock handler's scores and other accepted qualitative and quantitative methods. The Scorecard was used to evaluate 86 stockmen from 45 cattle feedyards in Texas. All subjects evaluated were stationed at locations between the crowd pen/tub and the chute, and the average score received was $84.5(\mathrm{SD}=14.73$, range $=100$ to 20$)$. Forty-five percent of the stockmen observed $(n=39)$ received a perfect score, or were documented to have performed one to two actions that would deduct points (see Figure 3-1). The most frequent mistakes observed were: Fills crowd pen/tub over half full $(n=29)$, Slow to add/remove pressure $(n=27)$, uses unnecessary noise $(n=25)$, stands in front of the animal and taps on rear $(n=24)$, and fails to regulate animal flow through a pinch point $(\mathrm{n}=22)($ see Table 3-2). In addition, other common mistakes where when the stockmen unintentionally worked in an animal's blindspot $(n=18)$ and were observed to be constantly, and unnecessarily, screaming or yelling at the cattle $(\mathrm{n}=13)$.

In other studies that have documented stockman actions towards beef cattle, there has been a high level of variability between operations and individual stockmen (Destrez, Haslin, \& Bovin, 2018; Hultgren, Wiberg, Berg, Cvek, \& Kolstrup, 2013; Ligon, 2014, Simon, Hoar, \& Tucker, 2016). In all cases, cattle that were subjected to increase intensity of human vocalization and physical contact were also perceived as more difficult to move through the handling system. Beef cattle stockman should make a conscientious effort to handle cattle in a way that stress is minimized. Aversive handling practices induce significant fear in cattle, which can cause serious losses in productivity, increased handling problems and related injuries to both animals and handlers, and diminished animal welfare (Rushen, Taylor, \& Passille., 1999). Specific cattle handling 
recommendations have been provided in published research (Grandin, 2015; Grandin, 2008; North American Meat Institute, 2013). Elevated stress has been shown to be caused when handlers scream and yell, crack whips, generate metallic noise by banging on gates, run at the animal and aggressively hit cattle (Waynert, Stookey, SchwartzkopfGenswein, Watts, \& Waltz, 1999; Grandin, 2008; Woiwode, Grandin, Kirch, \& Paterson, 2016).

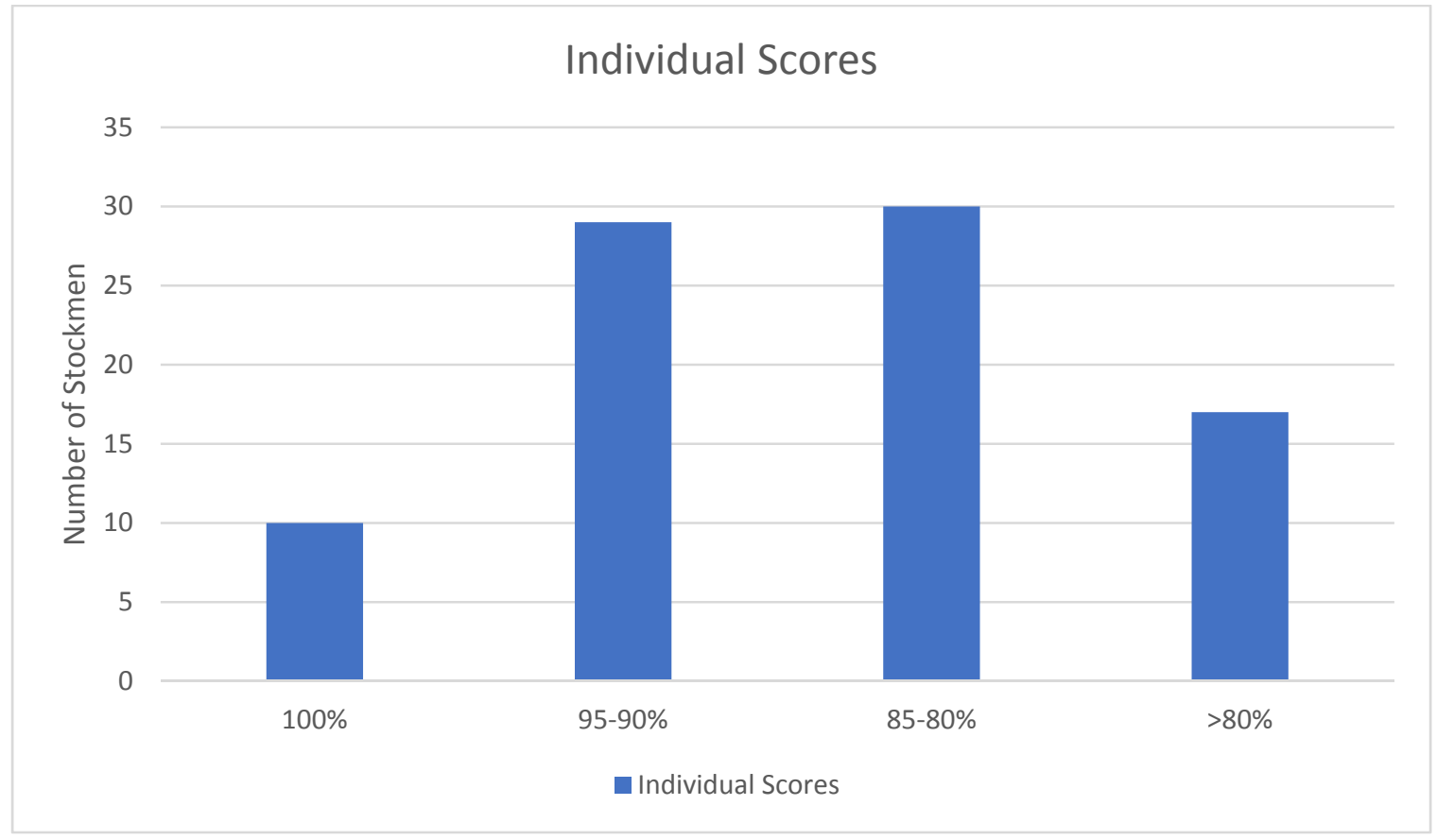

Figure 3-1: Individual Scores using the Stockman's Scorecard 
Table 3-1

Stockman's Scorecard Results

\begin{tabular}{|c|c|c|c|}
\hline Observation Point & $\begin{array}{l}\text { Points } \\
\text { deducted }\end{array}$ & \# Observed & $\begin{array}{l}\% \\
\text { Observed }\end{array}$ \\
\hline Valued team contributor & 0 & 78 & 91 \\
\hline Operates independent of team & -10 & 0 & 0 \\
\hline Ineffective team member & -5 & 8 & 9 \\
\hline Fills crowd pen $1 / 2$ full or less & 0 & 52 & 60 \\
\hline Over fills crowd pen & -10 & 2 & 2 \\
\hline Fills crowd pen over $1 / 2$ full & -5 & 29 & 34 \\
\hline Regulates cattle flow through pinch point & 0 & 58 & 67 \\
\hline Forces cattle through pinch point & -10 & 4 & 5 \\
\hline Fails to regulate cattle through pinch point & -5 & 22 & 26 \\
\hline Avoids working in cattle blindspot & 0 & 64 & 74 \\
\hline Continually works in blindspot & -10 & 3 & 3 \\
\hline Unintentionally works in blindspot & -5 & 18 & 21 \\
\hline Understands cattle's point of balance & 0 & 57 & 66 \\
\hline No Understanding of point of balance & -10 & 5 & 6 \\
\hline Stands in front of animal/taps rear & -5 & 24 & 28 \\
\hline Effectively uses flight zone pressure & 0 & 55 & 64 \\
\hline Excessive flight zone pressure & -10 & 3 & 3 \\
\hline Slow to add/remove pressure & -5 & 27 & 31 \\
\hline Unable to move group as a unit & -5 & 2 & 2 \\
\hline Uses appropriate amount of noise & 0 & 45 & 52 \\
\hline Intentionally generates metallic noise & -10 & 7 & 8 \\
\hline
\end{tabular}


Table 3-1 (continued)

Stockman's Scorecard Results

\begin{tabular}{lccc}
\hline Observation Point & $\begin{array}{l}\text { Points } \\
\text { deducted }\end{array}$ & \# Observed & $\begin{array}{l}\% \\
\text { Observed }\end{array}$ \\
\hline Constant/Unnecessary screaming/yelling & -10 & 13 & 15 \\
Unnecessary noise & -5 & 25 & 29 \\
Driving aid used appropriately & 0 & 69 & 80 \\
Electric Prod primary driving aid & -10 & 7 & 8 \\
Electric Pro applied at wrong time & -5 & 11 & 13 \\
Uses appropriate physical contact & 0 & 80 & 93 \\
Excessive/Unnecessary physical contact & -10 & 6 & 7 \\
Tail Twisting after animal movement & -5 & 0 & 0 \\
\hline
\end{tabular}

Stockmanship assessments were also conducted for the facility during scheduled BQA Feedyard Assessments. The Assessment uses six animal-based observations to determine the quality of stockmanship. For each observation point, thresholds have been established to determine whether the facility "passes" or "fails" on cattle handling. Of the 45 facilities visited, 24 failed on one or more categories on one or more visits. These 24 yards were visited a total of 53 times during the sampling period and there were 30 documented failures. Six of these facilities were only sampled once, two feedyards failed on all visits, and the remaining 16 passed on at least one of their other sampling dates. The most frequent cause of a failure was the use of electric prods (see Table 3-2). The number of facilities that failed animal handling assessment are higher than other reported observations (Barnhardt, 2015). The differences may be due to the fact that several of the 
yards we sampled were visited multiple times during the study period, instead of a single observation as previously described.

Several negative associations were found between a subject's score on the Scorecard and the animal-based measurements collected with the BQA Feedyard Assessment (see Table 3-3). A substantial negative association (Davis, 1971) was found between the number of animals touched with an electric prod and the subjects score on the noise and physical contact section $(\rho=-0.51)$. This high association should be expected as both tools collect a similar measurement. Points are lost in the noise and physical contact theme and deducted from the stockman's final score if an electric prod is used excessively or if contact is applied at the wrong time. The Assessment asks the observer to count the number of animals that are touched with the prod. Moderate negative associations (Davis, 1971) were found between the use of electric prods and the Situational Awareness $(\rho=0.31)$ score and Final Score $(\rho=-0.43)$ on the Scorecard. Also, moderate negative associations were found between the number of animals that vocalize in the chute prior to procedures and the final score $(\rho=-0.31)$ and herding skill $(\rho=-0.31)$ section on the scorecard. Grandin (1998) has identified animal vocalization as a key indicator of stress from adverse handling practices. She observed that skilled handlers averaged $4.5 \%$ animal vocalizations where plants with aggressive handling approached $22 \%$. 
Table 3-2:

BQA Feedyard Assessment Animal Observation Fails by Individual Feedyards

Observation Category \# of Fails Percent Fails

\begin{tabular}{lcc}
\hline Electric Prod Use & 15 & 20 \\
Fell when released from chute & 1 & 1 \\
Stumble/Tripped when released from chute & 8 & 9 \\
Vocalized in chute prior to procedures & 3 & 3 \\
Jumped/Ran when released from chute & 1 & 1 \\
Miscaught in head chute and not readjusted & 5 & 6 \\
\hline Single category fail & 15 & \\
Two category fail & 5 \\
\hline
\end{tabular}

Table 3-3:

Associations between the Scorecard and the BQA Feedyard Assessment

\begin{tabular}{lccc}
\hline Association & Spearman $\rho$ & P-value & $\begin{array}{c}\text { Strength of } \\
\text { Association }\end{array}$ \\
\hline BQA1 vs NP Total & -0.51 & $<0.0001$ & Substantial \\
BQA 1 vs Final Score & -0.43 & $<0.0001$ & Moderate \\
BQA 1 vs SA Total & -0.31 & 0.0038 & Moderate \\
BQA 4 vs Final Score & -0.31 & 0.0041 & Moderate \\
BQA 4 vs HS Total & -0.31 & 0.0041 & Moderate \\
\hline
\end{tabular}




\section{Qualitative Description of Stockman and Livestock Disposition}

The observers were asked to provide a one word, or short phrase, description of the handler's and the livestock's disposition. The majority of stockmen were described as being calm $(n=60)$ (see Table $3-4)$. There was an additional seven stockmen that were described as calm, but the observer also documented that they seemed rushed or were noisy. On fifteen evaluations the handlers were only described as being noisy, rushed, excited, jumpy, nervous, or frustrated. When describing the cattle being processed, 30 percent of the groups were categorized as being calm, while many groups where observed to be "slightly jumpy" $(\mathrm{n}=16)$ or "excited/wound up" (n=34). A small number of the groups $(\mathrm{n}=6)$, usually Holstein cattle, were described as being "stubborn."

\section{Table 3-4}

Handler and Livestock Disposition

\begin{tabular}{lcc}
\hline Handler Disposition & \# Observed & \% Observed \\
\hline Calm & 60 & 70 \\
Calm but rushed or noisy & 7 & 3 \\
Noisy & 3 & 6 \\
Rushed & 5 & 5 \\
Excited & 4 & 3 \\
Jumpy/Nervous/Frustrated & 3 & 30 \\
\hline Cattle Disposition & & 19 \\
\hline Calm & 26 & 37 \\
Slightly Jumpy & 16 & 7 \\
Excited/Wound Up & 34 & 6 \\
Stubborn & 6 & 3 \\
\hline
\end{tabular}


There was a moderate level of agreement (Stokes, Davis, \& Koch, 1995) between the qualitative description of the stockman's behavior and their final score using the Scorecard $($ Kappa $=0.44, \mathrm{p}$-value $<0.0001)$. Those stockmen that were observed to be calm in their actions tended to have a higher final score than those that were described as noisy, rushed, jumpy, nervous, or frustrated. A very slight agreement (Stokes, Davis, \& Koch, 1995) was found between the stockman's final score and the livestock disposition descriptor $(\mathrm{Kappa}=0.18, \mathrm{p}$-value $=0.01)$. In $43.9 \%$ of the cases where the livestock were described to have a negative disposition the stockman scored high on the scorecard and in $3.6 \%$ of the cases the livestock were described as "calm," but the stockman received a low score.

Significant correlations have been found between stockman behavior, animal behavior, and animal productivity (Ellingsen, Coleman, Lund, \& Meidell, 2014; Hemsworth, Coleman, Barnett, Borg, \& Dowling, 2002; Waiblinger, Menke, and Coleman, 2002). Livestock that are handled in a calm manner tend to behave calmer and have higher productivity than those that are handled more aggressively. We observed that there was a negligible association between handler score or disposition and animal behavior. The expressed behavior of cattle is related to a combination of environment, genetics, and handling factors (Grandin, 1994; Grignard, Boivin, Boiss, \& Neindre, 2001). Cattle may initially react negatively to any handling practice but can habituate over time (Petherick et al., 2009a; Petherick, Doogan, Venus, Holroyd, \& Olsson, 2009b), although they will not habituate to extremely adverse handling practices (Grandin, 1998). We were not able to observe every stockman involved in the handling 
activity, nor did we collect data on the age of the cattle and their time at the feeding facility. Repeated interactions with humans have shown to reduce reactivity of cattle in a feedlot setting (Doyle, 2014). It is also believed that cattle can differentiate between handlers that treat them poorly and handlers that are gentle (Munksgaard et al., 1997).

\section{Conclusions}

In order for an evaluation tool to be useful to measure the underlying construct it needs to be determined if it is valid and reliable. The Stockman's Scorecard has been previously determined to be both valid and reliable in measuring the quality of stockmanship. This paper has further strengthened the tool by establishing the criterionrelated validity of the instrument (Huck, 2012). To establish this type of validity, the new instrument is compared to current accepted measurement tools. The established associations between Scorecard's results and animal-based observations from the BQA Feedyard Assessment provide the criterion-related validity. Furthermore, we have been able to provide an association between an individual score and the stockman's behavior. The slight associate of the Scorecard results with a simple qualitative description of the cattle's behavior implies that the score received by the individual stockman was independent of the behavior of the livestock.

Assessment tools such as the BQA Feedyard Assessment, are able to identify if there are deficiencies in stockmanship. The Stockman's Scorecard allows a manager to now determine what may be the cause of these deficiencies and establish targeted training programs to improve a handler's stockmanship. This tool has multiple applications. It may be used in a pre-test/post-test format for educators to evaluate stockmanship training. It can be used by researchers to precisely define the stockmanship parameters of 
their animal handling studies. Future research should focus on evaluation of all stockmen involved in an animal handling activity to determine if a specific stockman can be identified as the cause of handling aberrations. There is also the opportunity to begin to determine the physiological effects of precise adverse handling conditions on animal outcomes. 


\section{REFERENCES}

Ary, D., Jacobs, L.C., Sorensen, C.K., \& Walker, D.A. (2012). Introduction to Research in Education. (9 ${ }^{\text {th }}$ ed.). Wadsworth: Cengage Learning.

Barnhardt, T.R. (2015). Implementation of industry-oriented welfare quality assurance assessment tools in commercial cattle feeding operations (Master's Thesis). Retrieved from K-State Research Exchange. (2015-0605T20:25:31Z)

Beef Quality Assurance Feedyard Assessment Guide (n.d). Retrieved from: https://www.bqa.org/Media/BQA/Docs/feedyard_assessment_2017.pdf

Birkenholz, R.H. (1993). Pilot study of agricultural literacy. University of Missouri. US Department of Agriculture. Retrieved from http://files.eric.ed.gov/fulltext/ED369890.pdf.

Boivin, X., Nowak, R., Despres, G., Tournadre, H., \& Neindre, P.L. (1997). Discrimination between shepherds by lambs reared under artificial conditions. Journal of Animal Science, 75, 2892-2989.

Boivin, X., Garel, J.P., Mante, A., \& Neindre, P.L. (1998). Beef calves react differently to different handlers according to the test situation and their previous interactions with their caretaker. Applied Animal Behaviour Science, 55, 245-257.

Butler, F.K. (2002). Medical support of special operations. In K.B. Randolph (Ed.), Textbook of Military Medicine: Medical aspects of harsh environments (Vol. 2, pp. 1128-1165). Falls Church: Office of the Surgeon General, US Army. Retrieved from 
https://ke.army.mil/bordeninstitute/published_volumes/harshEnv2/HE2ch 37.pdf.

Butler, R.K. \& Beading, C.W. (2014). Medical Support of Operations. In J.M. Ryan (Ed.), Conflict and Catastrophic Medicine: A Practical Guide (pp. 121-145). Springer. Retrieved from http://link.springer.com/book/10.1007/978-1-4471-2927-1.

Carmines, E.G., \& Zeller, R.A. (1979). Reliability and Validity Assessment (Vol. 17). Thousand Oaks, CA: Sage.

Cicchetti, D.V. (1994). Guidelines, criteria, and rules of thumb for evaluating normed and standardized assessment instruments in psychology. Psychological Assessment, 6(4), 284-290.

Coleman, G.L. \& Hemsworth, P.H. (2014). Training to improve stockperson beliefs and behavior towards livestock enhances welfare and productivity. Revue Scientifique et Technique (International Office of Epizootics), 33(1), 131-137.

Davis, J.A. (1971). Elementary survey analysis, Englewood Cliffs, NJ: PrenticeHall.

Destrez, A., Haslin, E., \& Boivin, X. (2018). What stockperson behavior during weighing reveals about the relationship between humans and suckling beef cattle: A preliminary study. Applied Animal Behaviour Science, 209, 813.

Doyle, R. (2014). Don't fence me in? The welfare of cattle in feedlots. 2014 Graham Centre Beef Forum. Retrieved from: 
https://www.csu.edu.au/_data/assets/pdf_file/0007/1180384/2014-BeefForum-Proceedings-WEB.pdf\#page $=23$.

Ellingsen, K., Coleman, G.J., Lund, V., \& Meidell, C.M. (2014). Using qualitative behavior assessment to explore the link between stockperson behavior and dairy calf behavior. Applied Animal Behaviour Science, 153, $10-17$.

Etim, N.N., Offiong, E.E.A., Udo, M.D., Williams, M.E., \& Evans, E.I. (2013). Physiological relationship between stress and reproductive efficiency. Agriculture and Biology Journal of North America. DOI:10.5251/anjna.2013.4.6.600.604.

Fukasawa, M. (2012). The calf training for loading onto vehicle at weaning. Animal Science Journal, 83(11), 759-766.

Gonyou, H.W. (1995). How animal handling influences animal behavior. Prairie Swine Centre, Inc. 1995 Annual Research Report. Retrieved from: http://www.prairieswine.com/pdf/2007.pdf.

Grandin, T. (1994). Solving livestock handling problems. Retrieved from: www.grandin.com/references/solv.lvstk.probs.html.

Grandin, T., Oldfield, J.E., \& Boyd, L.J. (1998). Reducing handling stress improves both productivity and welfare. The Professional Animal Scientist, 14(1), 1-10.

Grandin, T. (1998). The feasibility of using scoring as an indicator of poor welfare during cattle slaughter. Applied Animal Behaviour Science, 56(24), 121-128. 
Grandin, T. (2001). Livestock-handling quality assurance. Journal of Animal Science, 79(E suppl.), 239-248.

Grandin, T. \& Dessing, M. (2008). Humane livestock handling: Understanding livestock behavior and building facilities for healthier animals. By T. Grandin and M. Dessing. (eds.) Storey Publishing.

Grandin, T. (2014). Animal welfare and society concerns: finding the missing link. Meat Science, 98(3), 461-469.

Grandin, T. (2015). How to improve livestock handling and reduce stress. In T. Grandin (Ed.), Improving Animal Welfare: A Practical Approach. $\left(2^{\text {nd }}\right.$ ed., pp. 69-95). Wallingford: CAB International.

Grandin, T. \& Shively, C. (2015). How farm animals react and perceive stressful situations such as handling, restraint, and transport. Animals, 5(4), 12331251.

Grignard, L., Bovin, X., Boiss, A., Neindre, P.L. (2001). Do beef cattle react consistently to different handling situations? Applied Animal Behaviour Science, 71(4), 263-276.

Hallgren, K.A. (2012). Computing Inter-Rater Reliability for Observational Data: An Overview and Tutorial. Tutor Quant Methods Psychol, 8(1), 23-34.

Hemsworth, P.H., Coleman, G.J., Barnett, J.L., Borg, S., \& Dowling, S. (2002). The effects of cognitive behavioral intervention on the attitude and behavior of stockpersons and the behavior and productivity of commercial dairy cows. Journal of Animal Science, 80, 68-78. 
Huck, S.W. (2012). Reading statistics and research (6 ${ }^{\text {th }}$ ed.). Boston, MA: Pearson Education, Inc.

Hughes, J. and Hughes, T. (2009). Predeployment training recommendations for special forces medical sergeants based on recent Operation Enduring Freedom experiences. Journal of Special Operations Medicine, 9(4), 1619.

Hultgren, J., Wiberg, S., Berg, C., Cvek, K., \& Kolstrup, C. (2013). Cattle behaviors and stockperson actions related to impaired animal welfare at Swedish slaughter plants. Applied Animal Behaviour Science, 152, 23-37.

Kristjanson, P. (2010). Innovative research approaches for sustainable livestock production and poverty reduction in the developing world. Retrieved from https://cgspace.cgiar.org/handle/10568/3911.

Ligon, J.M. (2014). The effects of low stress cattle handling and weaning training on post-weaning weight gain and calf activity (Master Thesis). Retrieved from VtechWorks. (2015-02-05T09:00:41Z)

Lima, M.L.P., Negrao, J.A., Paz, C.C.P., Grandin, T. (2016). Effects of corral modifications for humane livestock handling on cattle behavior and cortisol release. Animals and Science: Big Solutions for Grand Challenges. Joint Annual Meeting of ASAS-ADSA-CSAS-WSASAS. Salt Lake City, UT. July 2016.

Luckey, A.N., Murphrey, T.P., Cummins, R.L., \& Edwards, M.B. (2013). Assessing youth perceptions and knowledge of agriculture: the impact of 
participating in an AgVenture program. Journal of Extension, 51(3). Retrieved from https://joe.org/2013june/rb3.php.

Matson, K.M. (2006). The effect of weekly handling on the temperament of peripuberal crossbred beef heifers (Master's Thesis). Retrieved from VtechWorks. (2014-03-14T20:38:27Z).

Munksgaard, L., Passille, A.M.D., Rushen, J., Thodberg, K., \& Jensen, M.B. (1997). Discrimination of people by dairy cows based on handling. Journal of Dairy Science, 80(6), 1106-1112.

North American Meat Institute (2013). Recommended animal handling guidelines and audit guide: A systematic approach to animal welfare. Retrieved from: http://www.animalhandling.org/ht/d/sp/i/26752/pid/26752.

Penner, G.B. (2011). US military peacebuilding and post-conflict reconstruction: Meeting the challenges of the post 9/11 environment (Masters Thesis). Retrieved from VtechWorks. (2014-03-14T20:49:33Z).

Preston, T.R. (1995). Strategy for sustainable use of natural resources: Constraints and opportunities. First FAO Electronic Conference on Tropical Feeds and Feeding Systems. Retrieved from http://www.fao.org/AG/Aga/FRG/ECONF95/HTML/PRESTON.HTM.

Passille, A.M., Rushen, J., Ladewig, J., \& Petherick, C. (1996). Dairy calves discrimination of people based on previous handling. Journal of Animal Science, 76(5), 969-974. 
Petherick, J.C., Doogan, V.J., Holroyd, R.G., Olsson, P., \& Venus, B.K. (2009a). Quality of handling and holding yard environment, and beef cattle temperament: 1. Relationships with flight speed and fear of humans. Applied Animal Behaviour Science, 120, 18-27.

Petherick, J.C., Doogan, V.J., Venus, B.K., Holroyd, R.G., \& Olsson, P. (2009b). Quality of handling and holding yard environment, and beef cattle temperament: 2. Consequences for stress and productivity. Applied Animal Behaviour Science, 120, 28-38.

Probst, J.K., Hillmann, E., Leiber, F., Kreuzer, M., \& Neff, S.N.(2013). Influence of gentle touching applied few weeks before slaughter on avoidance distance and slaughter stress in finishing cattle. Applied Animal Behaviour Science, 144, 14-21.

Reimert, I., Fong, S., Rodenburg, T.B., \& Bolhuis, J.E. (2017). Emotional states and emotional contagion in pigs after exposure to a positive and negative treatment. Applied Animal Behaviour Science, 193, 37-42.

Robinson, J.P., Shaver, P.R., \& Wrightsman, L.S. (1991). Criteria for scale selection and evaluation. In J.P. Robinson, P.R. Shaver, \& L.S. Wrightsman (Eds.). Measures of personality and social psychological attitudes (pp. 1-16), New York, NY: Academic Press.

Rocha, L.M., Belarde, A., Dalmav, A., Saucier, L., and Faucitano, L. (2016). Can the monitoring of animal welfare parameters predict pork meat quality variation through the supply chain (from farm to slaughter)? Journal of Animal Science. 94(1), 359-376. 
Rufolo, D. and Facciolla, C. (2011). Public Health in the JSOTF-P. Journal of Special Operations Medicine, 11(1), 4-7.

Rushen, J., Munksgaard, L., Passille, A.M.B. Jensen, M.B., \& Thodberg, K. (1998). Location of handling and dairy cows' responses to people. Applied Animal Behaviour Science, 55, 259-267.

Rushen, J., Taylor, A., \& Passille, A.M.D. (1999). Domestic animals' fear of humans and its effect on their welfare. Applied Animal Behaviour Science, 65, 285-303.

Rushen, J. \& Passille, A.M.D. (2015). The importance of good stockmanship and its benefits to animals. In T. Grandin (Ed.), Improving Animal Welfare: A Practical Approach. (2 $2^{\text {nd }}$ ed., pp. 125-138). Wallingford: CAB International.

Simon, G.E., Hoar, B.R., \& Tucker, C.B. (2016). Assessing cow-calf welfare. Part 1: Benchmarking beef cow health and behavior, handling; and management, facilities, and producer prospectives. Journal of Animal Science, 94(8), 3476-3487.

Stokes, M.E., Davis, C.S., \& Koch, G.G. (1995). Categorical data analysis using the SAS System, Cary, NC: SAS Institute, Inc.

Tallet, C., Kardiatou, S., Prunier, A., Noward, R., Boissy, A., \& Boivin, X. (2014). Behavioral and physiological reactions of piglets to gentle tactile interactions vary according to their previous experience with humans. Livestock Science, 167, 331-341.

Waiblinger, S., Menke, C., \& Coleman, G. (2002). The relationship between attitudes, personal characteristics and behavior of stockpeople and 
subsequent behavior and production of dairy cows. Applied Animal Behaviour Science, 79, 195-2019.

Waiblinger, S., Menke, C., \& Folsch, D.W. (2003). Influences on the avoidance and approach behavior of dairy cows towards humans on 35 farms. Applied Animal Behaviour Science, 84, 23-39.

Waynert, D.F., Stookey, J.M., Schartzkopt-Genswein, K.S., Watts, J.M., \& Waltz, C.S. (1999). The response of beef cattle to noise during handling. Applied Animal Behaviour Science, 62, 27-43.

Welfare Quality ${ }^{\circledR}$. (2009). Welfare Quality ${ }^{\circledR}$ assessment protocol for cattle. Welfare Quality ${ }^{\circledR}$ Consortium, Lelystad, Netherlands.

Woiwode, R., Grandin, T., Kirch, B., \& Paterson, J. (2016). Effects of initial handling practices on behavior and average daily gain of fed steers. International Journal of Livestock Production, 7(3), 12-18.

Zulkifli, I. (2013). Review of human-animal interactions and their impact on animal productivity and welfare. Journal of Animal Science and Biotechnology, 4(25). DOI: $10.1186 / 2049-1891-4-25$. 
VITA

John K. Yost

\section{Education}

\section{Professional Employment}

2016 to Present

$2011-2016$

$2001-2011$

$2000-2001$

2000

$1999-2000$
Master's Degree (M.A.) 1999

West Virginia University, Morgantown, WV Animal Science

Bachelor's Degree (B.S.) 1996

West Virginia University, Morgantown, WV Animal Sciences

Assistant Director, WVU Davis College

Farms, Morgantown, WV

Farm Operator, WVU Division of Animal

Sciences, Morgantown, WV

Extension Educator IV, ANR, Ohio State University Extension, Fayette County, Washington Courthouse, $\mathrm{OH}$

Site Manager, National Service Company, Little Rock, AR

Quality Assurance Supervisor, George's

Poultry Inc., Springdale, AR

Service Technician, Peterson Farms, Decatur, AR 